\title{
Tumor Findings Death Relationship
}

National Cancer Institute

\section{Source}

National Cancer Institute. Tumor Findings Death Relationship. NCI Thesaurus. Code C119927.

An indication or description of a correlation between death and a tumor finding. 